\title{
Disease associated balanced chromosome rearrangements: a resource for large scale genotype-phenotype delineation in man
}

Department of

Medical Genetics, IMBG, University of

Copenhagen,

Blegdamsvej 3,

DK-2200 Copenhagen

N, Denmark

M Bugge

E Niebuhr

K R Rasmussen

N Tommerup

Department of Clinical Genetics, Vejle

Hospital, Denmark

G Bruun-Petersen

John F Kennedy

Institute, Glostrup,

Denmark

K Brøndum-Nielsen

Institute of Human

Genetics, University of

Aarhus, Denmark

U Friedrich

Cytogenetic Registry, Department of Clinical Genetics, University Hospital, Aarhus,

Denmark

J Hansen

P K A Jensen

Chromosome

Laboratory, Institute of

Pathology,

Frederiksberg

Hospital, Denmark

G Jensen

Department of Clinical Genetics, University Hospital, Aarhus,

Denmark

P K A Jensen

Department of Clinical Genetics, University

Hospital, Lund,

Sweden

U Kristoffersson

Department of Clinical Genetics,

Rigshospitalet,

Copenhagen, Denmark

G Jensen

C Lundsteen

Department of Clinical Genetics, University

Hospital Odense,

Denmark

K Rasmussen

Correspondence to:

Dr Tommerup,

tommerup@imbg.ku.dk

Revised version received 28 May 2000

Accepted for publication

20 June 2000

\begin{abstract}
Merete Bugge, Gert Bruun-Petersen, Karen Brøndum-Nielsen, Ursula Friedrich, Jan Hansen, Grethe Jensen, Peter K A Jensen, Ulf Kristoffersson, Claes Lundsteen, Erik Niebuhr, Kim R Rasmussen, Kirsten Rasmussen, Niels Tommerup
\end{abstract}

\begin{abstract}
Disease associated balanced chromosomal rearrangements (DBCRs), which truncate, delete, or otherwise inactivate specific genes, have been instrumental for positional cloning of many disease genes.
\end{abstract} A network of cytogenetic laboratories, Mendelian Cytogenetics Network (MCN), has been established to facilitate the identification and mapping of DBCRs. To get an estimate of the potential of this approach, we surveyed all cytogenetic archives in Denmark and southern Sweden, with a population of $\sim 6.6$ million. The nine laboratories have performed 71739 postnatal cytogenetic tests. Excluding Robertsonian translocations and chromosome 9 inversions, we identified 216 DBCRs $(\sim 0.3 \%)$, including a minimum estimate of 114 de novo reciprocal translocations $(0.16 \%)$ and eight de novo inversions $(0.01 \%)$. Altogether, this is six times more frequent than in the general population, suggesting a causal relationship with the traits involved in most of these cases. Of the identified cases, only $25(12 \%)$ have been published, including 12 cases with known syndromes and 13 cases with unspecified mental retardation/congenital malformations. The remaining DBCRs were associated with a plethora of traits including mental retardation, dysmorphic features, major congenital malformations, autism, and male and female infertility. Several of the unpublished DBCRs defined candidate breakpoints for nailpatella, Prader-Willi, and Schmidt syndromes, ataxia, and ulna aplasia. The implication of the survey is apparent when compared with MCN; altogether, the 292 participating laboratories have performed $>2.5$ million postnatal analyses, with an estimated 7500 DBCRs stored in their archives, of which more than half might be causative mutations. In addition, an estimated 450-500 novel cases should be detected each year. Our data illustrate that DBCRs and MCN are resources for large scale establishment of phenotypegenotype relationships in man. ( $F$ Med Genet 2000;37:858-865)

Keywords: translocations; inversions; abnormal phenotypes; frequency
When the sequencing of the human genome is finished within the next one to three years, the presence and location of the estimated $60000-$ 100000 human genes will be known. However, knowledge about the function and potential involvement in human morbidity will only have been established for a tiny fraction of these genes. Therefore, large scale strategies to establish genotype-phenotype relationships will be of major importance.

One of the classical approaches for this is based on molecular characterisation of chromosomal breakpoints associated with abnormal phenotypes. Thus, disease associated balanced chromosome rearrangements (DBCRs) that truncate, delete, or otherwise inactivate specific genes have been instrumental in the positional cloning of many disease genes. ${ }^{12}$ Although most of these published DBCRs have been associated with well known disorders/syndromes, reports from population surveys, ${ }^{3}$ prenatal diagnosis, ${ }^{4}$ and surveys of mental retardation ${ }^{5}{ }^{6}$ suggest that they may be associated with a variety of different phenotypes and may be more frequent than usually anticipated.

Chromosome analysis is the most widespread routine genetic test in the world, offered by hundreds of diagnostic laboratories world wide. In order to systematise the identification of specific disease associated genes by mapping and cloning of breakpoints in DBCRs, the Mendelian Cytogenetic Network (MCN) has been established, at present involving 292 diagnostic cytogenetic laboratories world wide. The strategy, which involves submission of data on DBCRs into a central database (MCN $d b),{ }^{7}$ includes each laboratory identifying and reporting the karyotype and phenotype of the DBCRs that have been encountered both retrospectively and prospectively, in order to improve the chances of identifying disease specific breakpoints.

Since the potential of this approach will rely on the actual number and types of DBCRs that can be expected within MCN, we performed a systematic search in all cytogenetics archives in Denmark and the South Swedish Health Care Region (comprising four counties in southern Sweden (SSHCR)), and from this we estimated the frequency and types of DBCRs among postnatal chromosome samples.

\section{Materials and methods}

Cytogenetic analysis in Denmark and SSHCR started in the 1960s. In Denmark, analyses 
Table 1 Disease associated balanced chromosomal rearrangements (DBCR) in Denmark and southern Sweden

\begin{tabular}{lrcrrl}
\hline & $\begin{array}{l}\text { Total } \\
\text { analysis } \\
\text { No) }\end{array}$ & $\begin{array}{l}\text { DBCR } \\
\text { BTt } \\
\text { (No) }\end{array}$ & $\begin{array}{l}\text { DBCR } \\
\text { BIf } \\
\text { (No) }\end{array}$ & Total & $\begin{array}{l}\text { DBCR \% } \\
\text { of total } \\
\text { analysis }\end{array}$ \\
\hline 1 & 996 & 1 & 2 & 3 & 0.30 \\
2 & 5276 & 11 & 8 & 19 & 0.36 \\
3 & 19484 & 58 & 6 & 64 & 0.33 \\
4 & 3336 & 6 & 0 & 6 & 0.18 \\
5 & 8277 & 19 & 4 & 23 & 0.28 \\
6 & 10549 & 20 & 6 & 26 & 0.25 \\
7 & 9864 & 24 & 10 & 34 & 0.34 \\
8 & 644 & 2 & 0 & 2 & 0.31 \\
9 & 13313 & 28 & 11 & 39 & 0.29 \\
Total & 71739 & 169 & 47 & 216 & 0.30 \\
\hline
\end{tabular}

*1. Chromosome Laboratory, Frederiksberg Hospital, DK. 2. Department of Clinical Genetics, Vejle Hospital, DK. 3. John F Kennedy Institute, Glostrup, DK. 4. Institute of Medical Genetics, University of Copenhagen, DK. 5. Cytogenetic Laboratory, Aarhus Psychiatric Hospital, DK. 6. Department of Clinical Genetics, Rigshospitalet, Copenhagen, DK. 7. Department of Clinical Genetics, Aarhus University Hospital, DK. 7. Department of Clinical Genetics, Odense University Hospital, DK. 9. Department of Clinical Genetics, University Hospital, Lund, Sweden.

†Reciprocal balanced translocations and insertions.

$\ddagger$ Balanced inversions.

have been offered by eight cytogenetics laboratories and the SSHCR has been covered by one laboratory.

The search included the period from the inception of the individual laboratory until the end of 1997. The registration of cases and results of analysis, which initially were performed manually in six of the nine laboratories, have now been computerised, but at very different times in each laboratory. Thus, manual files cover 20 to 30 years of diagnosis. The Danish Cytogenetic Central Registry (DCCR), established in $1968,{ }^{8}$ is an electronic registry comprising all subjects with a chromosome analysis in Denmark, including those diagnosed before the registry was started. DCCR made a search on name, date of birth, date of analysis, and karyotype for five of the laboratories, listing all cases with translocations, insertions, and inversions, excluding Robertsonian translocations and the common chromosome 9 inversions. In one laboratory, the archive search was exclusively manual. Three laboratories, which have been computerised since the start, made a similar local search.

Table 2 Origin of disease associated balanced chromosome rearrangements (DBCR) in Denmark and southern Sweden

\begin{tabular}{|c|c|c|c|c|c|c|c|c|}
\hline \multirow[b]{2}{*}{ Laboratories* } & \multicolumn{4}{|c|}{ Translocations } & \multicolumn{4}{|l|}{ Inversions } \\
\hline & De novo & Matt & Pat $\neq$ & Unknown & De novo & Matt & Pat $\neq$ & Unknown \\
\hline 1 & 0 & 1 & 0 & 0 & 0 & 0 & 1 & 1 \\
\hline 2 & 2 & 6 & 1 & 2 & 1 & 2 & 1 & 4 \\
\hline 3 & 41 & 4 & 1 & 12 & 2 & 2 & 0 & 2 \\
\hline 4 & 4 & 0 & 1 & 1 & 0 & 0 & 0 & 0 \\
\hline 5 & 2 & 5 & 2 & 10 & 0 & 2 & 1 & 1 \\
\hline 6 & 13 & 1 & 1 & 5 & 2 & 1 & 1 & 2 \\
\hline 7 & 9 & 3 & 3 & 9 & 1 & 4 & 5 & 0 \\
\hline 8 & 0 & 0 & 0 & 2 & 0 & 0 & 0 & 0 \\
\hline 9 & 7 & 3 & 5 & 13 & 0 & 2 & 6 & 3 \\
\hline Total & 78 & 23 & 14 & 54 & 06 & 13 & 15 & 13 \\
\hline
\end{tabular}

*1. Chromosome Laboratory, Frederiksberg Hospital, DK. 2. Department of Clinical Genetics, Vejle Hospital, DK. 3. John F Kennedy Institute, Glostrup, DK. 4. Institute of Medical Genetics, University of Copenhagen, DK. 5. Cytogenetic Laboratory, Aarhus Psychiatric Hospital, DK. 6. Department of Clinical Genetics, Rigshospitalet, Copenhagen, DK. 7. Department of Clinical Genetics, Aarhus University Hospital, DK. 8. Department of Clinical Genetics, Odense University Hospital, DK. 9. Department of Clinical Genetics, University Hospital, Lund, Sweden.

†Mat: maternal origin.

$\ddagger$ Pat: paternal origin.
Each laboratory stores records of all the patients analysed in the period, including the referral diagnosis and often with some clinical data. Once identified, all the records were scrutinised in the individual laboratories by one of us (MB). In some cases, the clinical information was so sparse that it was necessary to contact the clinical department(s) involved and request additional information. Included in the study were all patients, postnatally karyotyped, with cytogenetically balanced reciprocal translocations, insertions, or inversions, which have a recorded pathological phenotype. Excluded were patients referred for repeated spontaneous abortions, when the carrier had an otherwise normal phenotype. In families where a pathological phenotype segregates with the rearrangement, only one member was included.

\section{Results}

Denmark has a population of $\sim 5.2$ million and the area in southern Sweden $\sim 1.4$ million. Thus the investigation covers a population of $\sim 6.6$ million persons. In the area, 71739 postnatal chromosome analyses were performed in the study period, 58426 in Denmark and 13313 in the laboratory in Lund, Sweden.

A total of 216 DBCRs were identified, 165 reciprocal balanced translocations, two balanced direct insertions, two inverted insertions, and 47 balanced inversions. The 216 DBCRs represent an average of $0.3 \%$ of all the analysed samples (table 1). Of the translocations, 78 were de novo, 23 were of maternal, 14 of paternal, and 54 of unknown origin, whereas the corresponding figures for the inversions were six de novo, 13 of maternal, 15 of paternal, and 13 of unknown origin (table 2). The four insertions were included in the translocation group for simplicity.

DBCRs were discovered in 53 subjects $(24 \%$ of the total) with 38 well known syndromes/ phenotypes (appendix, 1-4). The most common clinical feature was mental retardation (MR) with or without dysmorphism and/or congenital malformations and/or additional neurological symptoms. MR was associated with 88 translocations and 20 inversions representing $50 \%$ of the total number (appendix, 14). The next most common groups were male infertility with 14 translocations and five inversions (appendix, 12) and female infertility with 13 translocations and two inversions (appendix, 13).

\section{Discussion}

Autosomal reciprocal balanced translocations and inversions occur in approximately $0.1 \%$ of newborns ${ }^{3}$ and the estimated frequency of de novo balanced rearrangements in the general population, as determined from newborn screening series and from prenatal diagnosis, is $0.0283 \%{ }^{4}$ The systematic search disclosed 216 DBCRs, which represents an average of $0.3 \%$ of all the analyses. Moreover, the $0.3 \%$, which was remarkably similar in all but one of the Danish laboratories, was also observed in the Swedish laboratory. 
The de novo cases will probably be those cases with the highest probability of detecting disease specific breakpoints. However, we included all DBCRs irrespective of their type (de novo, paternal or maternal origin, with or without concordant traits, or unknown origin) since we did not want to exclude anything, for example, potentially de novo cases among the 67 DBCRs of unknown origin.

Of the 115 translocations where both parents had been analysed, $2 / 3$ of the cases (78/115) were de novo rearrangements. If we take the conservative view that $2 / 3$ of the 54 translocations of unknown status are also of de novo origin, the estimated number of de novo translocations in our survey would be $78+2 /$ $3{ }^{\star} 54=114(\sim 0.16 \%)$. In fact, since the mother had been excluded from carrying the rearrangement in six of the unknown cases, this must actually be a minimum estimate. Only $6 / 34$ of the inversions where both parents had been analysed were of de novo origin, so the total estimated numbers of de novo inversions would be $6+6 / 34^{\star} 13 \sim 8(\sim 0.01 \%)$. Combined, the estimated minimal frequency of de novo reciprocal translocations and inversions associated with abnormal phenotypes in our survey was $\sim 0.17 \%$, or a six-fold increase compared to the general population, suggesting that in the majority of these DBCRs the rearrangement will be causatively linked to the observed trait(s).

The population frequency of familial DBCRs with discordance for an abnormal phenotype is unknown, but it is conceivable that many if not most of these cases in our survey may be coincidental findings. However, we included these cases since they might be the ones associated with autosomal recessive disorders $^{9}$ and, as illustrated by the familial, discordant DBCRs associated with BeckwithWiedemann syndrome, ${ }^{10}$ associated with sex dependent imprinting.

Of the 52 cases with well known syndromes/ phenotypes, which in most cases can be accessed as specific entities in OMIM (appendix, 1-4), only 13 or $6 \%$ of the 216 DBCRs have been published previously in relation to the abnormal phenotype. ${ }^{10-22}$ One immediate consequence of the present study was the first fine mapping of a balanced chromosomal breakpoint within the Prader-Willi syndrome (PWS) chromosome region in a patient with PWS stigmata. ${ }^{23}$ Since then, additional translocation breakpoints involving the PWS imprinted region have been characterised. ${ }^{24-26}$ Furthermore, FISH mapping of an identified $t(1 ; 9)$ associated with nail-patella syndrome (NPS1) has narrowed the 9q34 breakpoints in this and in another NPS1 associated translocation $^{27}$ to a single PAC clone, which has been shown to contain the NPS1 lim-homeobox gene $L M X 1 B .^{28}$

In the PWS case, the karyotype was performed in 1979, and although microdeletions at 15q11-13 were not described before $1981,{ }^{29}$ numerous reports had suggested an involvement of chromosome 15 in PWS. ${ }^{29}{ }^{30}$ In the NPS1 case, which was also karyotyped in 1979, the balanced translocation was not considered to be associated with the phenotype despite the fact that NPS1 was mapped to 9q34 in $1976 .{ }^{31}$ These two cases illustrate that cytogenetic archives may contain DBCRs associated with well known disorders with known or suspected chromosomal locations, which may only be disclosed by systematic re-examination.

The survey uncovered several other DBCRs associated with specific genetic entities which are now under investigation: a familial $\mathrm{t}(6 ; 14)$ segregating with Schmidt syndrome (MIM $269200)$; a de novo $\mathrm{t}(2 ; 10)$ associated with ulnar aplasia; and a de novo inv(3) associated with radial aplasia. The cause of Cornelia de Lange syndrome (MIM 122470) is unknown, but two patients with different inversions have concordant involvement of $12 \mathrm{p} 13$. In addition, a $t(8 ; 20)$ segregating with atypical cerebellar ataxia in a large family suggests a putative locus for early onset mild ataxia at either $8 \mathrm{p} 21$ or 20q12 (Hertz et al, in preparation).

Mental retardation (MR) is one of the most common abnormal traits in man and the single most important indication for a chromosome analysis. In line with this, non-syndromal and syndromal MR, with or without other neurological symptoms, was the most common trait associated with DBCRs, seen in $108(50 \%)$ of the 216 cases. The fact that almost any visible chromosomal imbalance will result in mental impairment probably indicates that haploinsufficiency of numerous genes may lead to abnormal mental development. Still, relatively few specific genetic causes of MR have been characterised so far, including some forms of X linked MR, where specific DBCRs have aided in the characterisation of the genetic defects. ${ }^{32-34}$

Some of the apparently balanced rearrangements associated with MR may be unbalanced at the molecular level. Recent mapping of six DBCRs with mental retardation with breakpoints on chromosome 13 showed submicroscopic deletions in two cases, one of which originated from this survey. ${ }^{35}$ If we can extrapolate, a substantial fraction of DBCRs associated with MR may be associated with microdeletions, and as such may help specify novel microdeletion syndromes.

Another strategy to identify candidate breakpoints and genes associated with $M R$ is to identify common breakpoints associated with MR. In this study we observed two to four cases with mental retardation and the following common breakpoints: 1p36, 1q31, 1q44, 2q23, 4p16, 4q22, 4q35, 5q13, 6q27, 7q22, 7q36, 9p24, 9q34, 12q15, 13q34, and 14q32. Interestingly, half of these 16 clusters involve telomeric cytogenetic bands (appendix, 13), and altogether 29 of the 238 breakpoints detected in association with mental retardation occurred in telomeric cytogenetic bands. Haploinsufficiency of subtelomeric regions are frequently detected in idiopathic $M R,{ }^{36}{ }^{37}$ indicating that these regions must contain MR related genes. Therefore, DBCRs with terminal breakpoints may be good candidates for defining some of these genes, for example, by the presence of subtle microdeletions, truncating events, or other inactivation mechanisms. However, the observed clustering outside the telomeric 
regions suggests that DBCRs in general may be instrumental in the delineation of autosomal genes, which cause MR by haploinsufficiency.

Of the 108 cases with MR, only 12 cases have been published in relation to their phenotype, and none has been published since 1982 (Skovby and Niebuhr ${ }^{38}$ (two cases), Kristoffersen et $a l^{39}$ (two cases), Rasmussen et $a l^{40}$ (five cases)) ${ }^{41}{ }^{42}$ Most of the DBCRs associated with MR were diagnosed in the newborn period and later clinical examinations have not been reported. Some of these conditions may represent specific syndromes or may later have manifested more specific or additional symptoms and a systematic clinical follow up would be of great value. Although this is very time consuming and has only been done in a limited number of patients, we plan to do this.

Infertility is the second largest group that was identified. Among the cases with female infertility, eight involve X;autosomal translocations, all of which have a breakpoint at Xq21-23 within the known critical region on the $\mathrm{X}$ chromosome. ${ }^{43}$ However, almost as frequent (seven cases) are rearrangements only involving autosomes. Since very little is known about autosomal genes in female infertility, such DBCR may become important for genetic exploration of female infertility. In the group of male infertility, chromosome 1 is involved in four rearrangements and in three of them the breakpoint is at $1 \mathrm{q} 21$, whereas $2 \mathrm{q} 21$ is a common breakpoint in two other cases.

It is at present speculative whether reciprocal translocations can cause infertility by disrupting genes involved in spermatogenesis/ oogenesis, or whether the infertility is associated with a mechanical disruption of the segregation of chromosomes. However, in the latter case it would be expected that chromosomes 1 and 2, which are of almost similar size, would be affected to a similar degree. Although we observed clustering of breakpoints in male infertility on both chromosomes in the present study, chromosome 1 has significantly more breakpoints than chromosome 2 (van Assche et $a l$, in preparation), suggesting that the location of the breakpoint is important too.

Among the 14 DBCRs associated with well known disorders with a mapped locus (appendix, 1, 2, and 3), only three DBCRs involved breakpoints outside the proven disease region: an inv(8) associated with Williams syndrome (with proven deletion of the ELN gene on chromosome 7 (data not shown)), a $\mathrm{t}(13 ; 18)$ associated with adrenogenital syndrome (with proven mutation of CYP21 on chromosome 6 (data not shown)), and an $\operatorname{inv}(2)$ associated with Rett syndrome with a proven mutation of the $\mathrm{X}$ linked $M E C P 2$ gene (Nielsen et al, in preparation) (appendix, 3). This is also consistent with the notion that the majority of DBCRs detected in the present study are causally related to the associated abnormal phenotypes.

In conclusion, we have shown in a survey of our population, which is as complete as it can be, that $\sim 0.3 \%$ of all postnatal cytogenetic analyses are DBCRs; this includes DBCRs associated with both mapped and unmapped but well known disorders/syndromes. More than half of the DBCRs were associated with mental retardation; some of these may be associated with microdeletions at the molecular level, and a remarkable number of MR associated breakpoints were clustered in specific cytogenetic regions. This clustering may indicate the location of specific MR genes. Although the geographical area covered by the study is rather limited, both with respect to population (6.6 million) and number of postnatal analyses performed (71 739), the importance of these figures is evident if we extrapolate to MCN. Altogether, the 292 participating laboratories have performed more than 2.5 million postnatal analyses, suggesting that their archives contain information on more than 7500 DBCRs, of which only a small fraction will have been published. In addition, the 292 participating laboratories perform more than 150000 postnatal analyses annually, suggesting that they will encounter 450-500 novel DBCRs each year. It will be no trivial matter to uncover these cases, especially in larger laboratories, but the present study illustrates that it will be worthwhile to do it in a systematic fashion and that pooling of such data within $\mathrm{MCN}$ can become a significant resource for large scale establishment of phenotype-genotype relationships in man.

This work was supported by the Danish Biotechnological Research and Development Programme 1996-1998, the Danish Environmental Research Programme, the Danish Research Councils (9700832), the Danish Cancer Society, Novo Nordisk Foundation, Aage Bangs Foundation, the German Programme/ Deutsche Forschungsanstalt für Luft-und Raumfart eV (4763), and the EU Commission (BMH4-CT97-2268). URLs for data in this article are as follows: Online Mendelian Inheritance in Man (OMIM), http://www3 ncbi.nlm.nih.gov/Omim/ and Mendelian Cytogenetics Network Database (MCNdb), http:// mondb.imbg.ku.dk/

1 Tommerup N. Mendelian cytogenetics. Chromosome rearrangements associated with Mendelian disorders. $f \mathrm{Med}$ Genet 1993;30:713-27.

2 Collins FS. Positional cloning moves from perditional to traditional. Nat Genet 1995;9:347-50. Published erratum in Nat Genet 1995;11:104.

3 Nielsen J, Sillesen I. Incidence of chromosome aberrations among 11148 newborn children. Hum Genet 1975;30:112 .

4 Warburton D. De novo balanced chromosome rearrangements and extra marker chromosomes identified at prenaments and extra marker chromosomes identified at prenapoints. Am f Hum Genet 1991;49:995-1013.

5 Jacobs PA. Correlation between euploid structural chromosome rearrangements and mental subabnormality in humans. Nature 1974;249:136-65.

6 Funderburk SJ, Spence MA, Sparkes RS. Mental retardation associated with "balanced" chromosome rearrangements. Am f Hum Genet 1977;29:136-41.

7 Nature Genetics news \& views ... and a cytogenetic database. Nat Genet 1999;22:321.

8 Nielsen J. The Danish Cytogenetic Central Register. Organization and results. Topics Hum Genet 1980;5:1-86.

9 Buhler EM. Unmasking of heterozygosity by inherited balanced translocations. Implications for prenatal diagnosis and gene mapping. Ann Genet 1983;26:133-7.

10 Tommerup N, Brandt CA, Pedersen S, Bolund L, Kamper J. Sex dependent transmission of Beckwith-Wiedemann syndrome associated with a reciprocal translocation syndrome associated with a reciprocal translocat
$\mathrm{t}(9 ; 11)(\mathrm{p} 11.2 ; \mathrm{p} 15.5)$. F Med Genet 1993;30:958-61.

11 Friedrich U, Nielsen J. Autosomal reciprocal translocations in newborn children and their relatives. Hum Genet 1974;21:133-44.

2 Tinning S, Jacobsen P, Mikkelsen M. A $(1 ; 6)$ translocation associated with congenital glaucoma and cleft lip and palate. Hum Hered 1975;25:453-60.

13 Sorensen K, Nielsen J, Holm V, Haahr J. Fragile site long arm chromosome 16. Hum Genet 1979;48:131-4.

14 Petersen F, Knudsen FU, Nielsen MD, Mikkelsen M. Congenital adrenal hyperplasia associated with a balanced genital adrenal hyperplasia associated with a b

15 Tommerup N, Nielsen F. A familial reciprocal translocation $\mathrm{t}(3 ; 7)(\mathrm{p} 21.1 ; \mathrm{p} 13)$ associated with the Greig polydactylycraniofacial anomalies syndrome. Am $\mathcal{f}$ Med Genet 1983;16:313-21. 
16 Nielsen LB, Nielsen IM. Turner's syndrome and Duchenne muscular dystrophy in a girl with an X;autosome translocation. Ann Genet 1984:27:173-7.

17 Tranebjaerg L, Sjo O, Warburg M. Retinal cone dysfunction and mental retardation associated with a de novo balanced translocation 1;6(q44;q27). Ophthalmic Paediatr Genet 1986;7:167-73

18 Baggesen K, Friedrich U, Jensen PKA, Rasmussen K. Three large Danish families with paracentric inversion in the short arm of chromosome no 5. Ann Genet 1988;31:50-2.

19 Gerdes AM, Petersen MB, Schrøder HD, Wulff K, Brøndum-Nielsen K. Congenital myopathy with fiber type disproportion: a family with a chromosomal translocation $\mathrm{t}(10 ; 17)$ may indicate candidate gene regions. Clin Genet 1994;45:11-16.

20 Warburg M, Bugge M, Brøndum-Nielsen K. Cytogenetic findings indicate heterogeneity in patients with blepharophimosis, epicanthus inversus and developmental delay. $\mathcal{F}$ Med Genet 1995;32:19-24.

21 Gustavsson P, Skeppner G, Johansson B, Berg T, Gordon L, Kreuger A, Dahl N. Diamond-Blackfan anaemia in a girl with a de novo balanced reciprocal X;19 translocation. $\mathcal{F}$ with a de novo balanced recip

22 Brandt CA, Lüdecke HJ, Hindkjær J, Strømkjær H, Pinkel $\mathrm{D}$, Herlin T, Bolund L, Friedrich U. A de novo complex $\mathrm{t}(7$ $13 ; 8)$ translocation with a deletion in the TRPS gene region. Hum Genet 1997;100:334-8.

23 Schultze A, Hansen C, Skakkebæk NE, Brøndum-Nielsen K, Ledbetter DH, Tommerup N. Exclusion of SNRPN as a major determinant of Prader-Willi syndrome by a translocation breakpoint. Nat Genet 1996;12:452-4.

24 Sun Y, Nicholls RD, Butler MG, Saitoh S, Hainline BE Palmer CG. Breakage in the SNRPN locus in a balanced $46, \mathrm{XY}, \mathrm{t}(15 ; 19)$ Prader-Willi syndrome patient. Hum Mol Genet 1996;5:517-24

25 Conroy JM, Grebe TA, Becker LA, Tsuchiya K, Nicholls RD, Buiting K, Horsthemke B, Cassidy SB, Schwartz S Balanced translocation $46, \mathrm{XY}, \mathrm{t}(2 ; 15)(\mathrm{q} 37.2 ; \mathrm{q} 11.2)$ associated with atypical Prader-Willi syndrome. Am ₹ Hum Genet ated with atypical

26 Kuslich CD, Kobori JA, Mohapatra G, Gregorio-King C, Donlon TA. Prader-Willi syndrome is caused by disruption of the SNRPN gene. Am f Hum Genet 1999;64:70-6.

27 Duba HC, Erdel M, Loffler J, Wirth J, Utermann B, Utermann G. Nail patella syndrome in a cytogenetically balanced $\mathrm{t}(9 ; 17)(\mathrm{q} 34.1 ; \mathrm{q} 25)$ carrier. Eur $\mathcal{f}$ Hum Genet 1998;6:75-9.

28 Silahtarogh Geurds MPA, Knoers NVAM, Mariman ECM, Tümer Z, Utermann G, Wirth J, Bugge M, Tommerup N. Molecula cytogenetic detection of $9 \mathrm{q} 34$ breakpoints associated with nail patella syndrome. Eur f Hum Genet 1999;7:68-76.

29 Ledbetter DH, Riccardi VM, Airhart SD, Strobel RJ, Keenan BS, Crawford JD. Deletions of chromosome 15 as a cause of the Prader-Willi syndrome. N Engl f Med 1981; 304:325-9.

30 Kousseff BG. The cytogenetic controversy in the PraderLabhart-Willi syndrome. Am ₹ Med Genet 1982;13:431-9. 1 Ferguson-Smith MA, Aitken DA, Turleau C, de Grouchy J. Localisation of the human AB0:Np-1: AK-1 linkage group by regional assignment of AK-1 to 9q34. Hum Genet 1976; 34:35-43.
32 van der Maarel SM, Scholten IH, Huber I, Philippe C, Suikerbuijk RF, Gilgenkrantz S, Kere J, Cremers FP, Ropers $\mathrm{HH}$. Cloning and characterization of DXS6673E, a candidate gene for X-linked mental retardation in Xq13.1. Hum Mol Genet 1996;5:887-97.

33 Billuart P, Bienvenu T, Ronce N, des Portes V, Vinet MC, Zemni R, Crollius HR, Carrie A, Fauchereau F, Cherry M, Briault S, Hamel B, Fryns JP, Beldjord C, Kahn A, Moraine C, Chelly J. Oligophrenin-1 encodes a rhoGAP protein involved in X-linked mental retardation. Nature 1998;392:923-6.

34 Gleeson JG, Allen KM, Fox JW, Lamperti ED, Berkovic S, Scheffer I, Cooper EC, Dobyns WB, Minnerath SR, Ross ME, Walsh CA. Doublecortin, a brain-specific gene mutated in human X-linked lissencephaly and double cortex syndrome, encodes a putative signaling protein. Cell 1998;92:63-72.

35 Wirth J, Nothwang HG, van de Maarel S, Menzel C, Borck G, Lopez-Pajares I, Brøndum-Nielsen K, Tommerup N, Bugge M, Ropers HH, Haaf T. Systematic characterisation of disease associated balanced chromosome rearrangements by FISH: cytogenetically and genetically anchored YACs idendify microdeletions and candidate regions for mental retardation genes. 7 Med Genet 1999;36:271-8.

36 Riegel M, Castellan C, Balmer D, Brecevic L, Schinzel A. Terminal deletion, del(1)(p36.3), detected through screenng for terminal deletions in patients with unclassified ma formation syndromes. Am F Med Genet 1999;82:249-53.

37 Slavotinek A, Rosenberg M, Knight S, Gaunt L, Fergusson RH, Flint J, Donnai D, Biesecker L. Screening for submicroscopic chromosome rearrangements in children with idiopathic mental retardation using microsatellite markers for the chromosome telomeres. F Med Genet 1999; 36:405-11.

38 Skovby F, Niebuhr E. Presumably balanced translocations involving the same band of chromosome no 4 found in two mentally retarded, dysmorphic individuals. Ann Genet 1974;17:243-9.

39 Kristoffersen L, Howitz P, Nathan E, Lundsteen C. [The clinical importance of chromosome abnormalities. Some problems illustrated by 2 examples]. (In Danish.) Ugeskr Laeg 1974;136:1628-30.

40 Rasmussen K, Nielsen J, Dahl G. The prevalence of chromosome abnormalities among mentally retarded persons in a geographically delimited area of Denmark. Clin Genet 1982;82:244-55.

41 Friedrich U, Dalby M, Staehelin-Jensen T, Bruun-Petersen G. Chromosomal studies of children with developmental language retardation. Dev Med Child Neurol 1982;24:64552

42 Nielsen J, Krag-Olsen B. Follow-up of 32 children with autosomal translocations found among 11,148 consecutively newborn children from 1969 to 1974. Clin Genet 1981;20:48-54.

43 Powell CM, Taggart RT, Drumheller TC, Wangsa D, Qian C, Nelson LM, White BJ. Molecular and cytogenetic studies of an X;autosome translocation in a patient with premature ovarian failure and review of the literature. Am $\mathcal{f} \mathrm{Med}$ Genet 1994;52:19-26.

Appendix Karyotype and phenotype of 216 disease associated balanced chromosome rearrangements (DBCR)

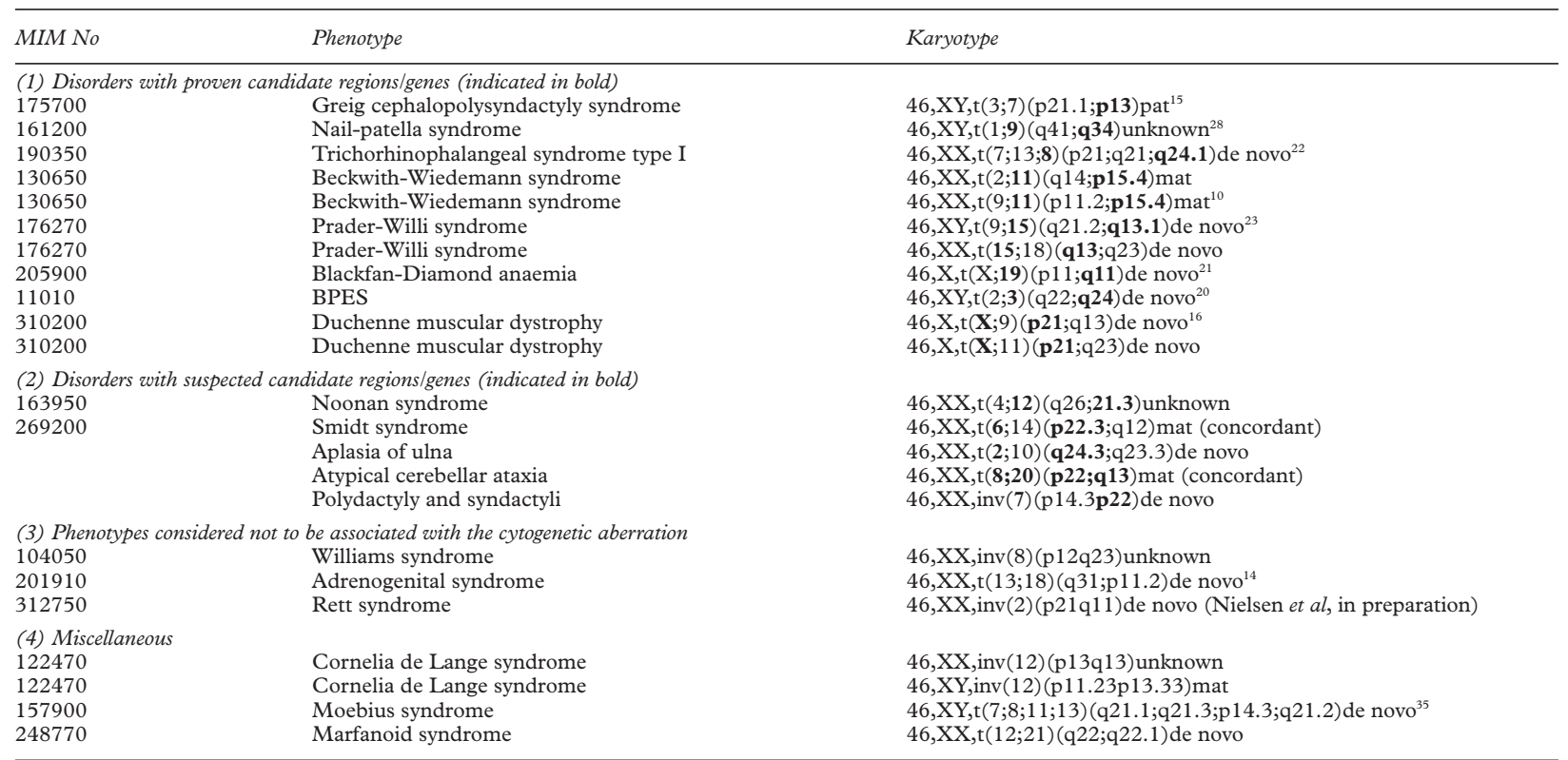


Appendix Continued




Appendix Continued

Phenoty

(14) Mental retardation with or without multiple congenital malformations Cases with cytogenetically matching breakpoints

$1 \mathrm{q} 31$

$1 \mathrm{q} 44$

$2 q 23$

4 p16

$4 \mathbf{q 2 2}$

$4 q 35$

$5 q 13$

$6 q 27$

$7 \mathbf{q} 22$

$7 \mathbf{q} 36$

9p24

$9 q 34$

$12 q 15$

$13 q 34$

$14 q 32$

$\star$, $†$, and $\ddagger$ : same cases with two different matching breakpoints Cases without cytogenetically matching breakpoints
Karyotype

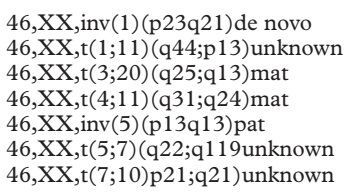

$46, \mathrm{XX}, \operatorname{inv}(1)(\mathrm{p} 23 \mathrm{q} 21)$ de novo

$46, \mathrm{XX}, \mathrm{t}(1 ; 11)(\mathrm{q} 44 ; \mathrm{p} 13)$ unknown

$46, \mathrm{XX}, \mathrm{t}(3 ; 20)(\mathrm{q} 25 ; \mathrm{q} 13) \mathrm{mat}$

$46, \mathrm{XX}, \mathrm{t}(4 ; 11)(\mathrm{q} 31 ; \mathrm{q} 24) \mathrm{mat}$

$46, \mathrm{XX}, \operatorname{inv}(5)$ (p13q13)pat

$46, \mathrm{XX}, \mathrm{t}(5 ; 7)$ (q22;q119unknown

$46, X X, t(7 ; 10)$ p $21 ; q 21)$ unknown

46, $\mathrm{XX}, \mathrm{t}(1 ; 4)(\mathrm{q} 31 ; \mathrm{q} 21), \mathrm{t}(2 ; 13)(\mathrm{p} 14.1 ; \mathrm{q} 33)$ de novo

$46, \mathrm{XY}, \mathrm{t}(1 ; 16)(\mathrm{q} 31 ; \mathrm{q} 13)$ pat

$46, \mathrm{XX}, \mathrm{t}(1 ; 19)(\mathrm{q} 44 ; \mathrm{q} 13.2)$ pat

$46, \mathrm{XY}, \mathrm{t}(1 ; 4)(\mathrm{q} 44 ; \mathrm{q} 22)$ de novo $^{38 \star}$

$46, X Y, t(1 ; 22)$ (q44; q11.9) unknown

$46, X X, t(1 ; 2)(\mathrm{p} 36 ; \mathrm{q} 23)$ unknown $^{40}$

$46, \mathrm{XX}, \mathrm{t}(2 ; 5)(\mathrm{q} 23.1 ; \mathrm{p} 13.1) \mathrm{pat}$

$46, \mathrm{XY}, \operatorname{inv}(2)(\mathrm{p} 23 \mathrm{q} 23.1)$ de novo

46,XY,t $(2 ; 4)$ (q23;q35)mat†

$46, \mathrm{XX}, \mathrm{t}(2 ; 16)(\mathrm{q} 23.2 ; 22.1)$ de novo

$46, X X$, inv ins (2) (p23q37q23)de novo

$46, X Y, \operatorname{inv}(4)$ (p16q11)pat

$46, \mathrm{XX}, \operatorname{inv}(4)(\mathrm{p} 16 \mathrm{q} 21.1) \mathrm{mat}, \operatorname{inv}(4)$ (p15.1q13)pat

$46, \mathrm{XX}, \mathrm{t}(4 ; 9)(\mathrm{q} 22 ; \mathrm{p} 24) \mathrm{pat}^{38}$

$46, \mathrm{XY}, \mathrm{t}(1 ; 4)(\mathrm{q} 44 ; \mathrm{q} 22) \mathrm{de}$ novo $^{38 \star}$

$46, \mathrm{XY}, \mathrm{t}(2 ; 4)$ (q23;q35)mat $\dagger$

$46, \mathrm{XX}, \mathrm{t}(4 ; 5)(\mathrm{q} 35 ; \mathrm{p} 12)$ de novo $^{39}$

$46, \mathrm{XX}, \mathrm{t}(5 ; 7)$ (q13;p13)unknown

$46, \mathrm{XX}, \mathrm{t}(5 ; 9)(\mathrm{q} 13 ; \mathrm{q} 22) \mathrm{pat}$

$46, \mathrm{XY}, \mathrm{t}(5 ; 8)(\mathrm{q} 13 ; \mathrm{q} 11)$ de novo

$46, \mathrm{XY}, \mathrm{t}(5 ; 15)(\mathrm{q} 13 ; \mathrm{q} 25) \mathrm{mat}^{42}$

$46, \mathrm{XX}, \operatorname{inv}(6)(\mathrm{p} 12 \mathrm{q} 27) \mathrm{mat}$

46,XX,t(6;13)(q27;q14)unknown

$46, \mathrm{XX}, \mathrm{t}(2 ; 7)(\mathrm{q} 31 ; \mathrm{q} 22)$ pat

$46, \mathrm{XX}, \mathrm{t}(6 ; 7)(\mathrm{p} 25 ; \mathrm{q} 22) \mathrm{mat}$

$46, \mathrm{XX}, \mathrm{t}(7 ; 13)(\mathrm{q} 22 ; \mathrm{q} 34)$ de novoł

$46, X X, t(1 ; 7)(\mathrm{p} 35 ; \mathrm{q} 36)$ unknown $^{40}$

$46, \mathrm{XX}, \mathrm{t}(1 ; 7)(\mathrm{p} 22 ; \mathrm{q} 36)$ inv (9)mat

46,XX,inv(9) (p13p24)unknown

$46, \mathrm{XX}, \mathrm{t}(9 ; 12)$ (p24;q21.2)de novo

$46, \mathrm{XY}, \mathrm{t}(9 ; 12)$ (q34; 13 ) de novo

$46, \mathrm{XY}, \mathrm{t}(9 ; 17)(\mathrm{q} 34.1 ; \mathrm{q} 25.3)$ de novo

$46, \mathrm{XY}, \mathrm{t}(2 ; 12)(\mathrm{p} 15 ; \mathrm{q} 15)$ de novo

$46, \mathrm{XY}, \mathrm{t}(7 ; 12)(\mathrm{q} 11 ; \mathrm{q} 15) \mathrm{mat}$

46,XX,inv(12)p13q15)mat

$46, \operatorname{XXt}(7 ; 13)$ (q22;q34)de novo

$46, \mathrm{XX}, \mathrm{t}(2 ; 13)(\mathrm{p} 24 ; \mathrm{q} 34) \mathrm{mat}$

$46, \mathrm{XX}, \mathrm{t}(12,13 ; 14 ; 20)(\mathrm{p} 11 ; \mathrm{q} 14 ; \mathrm{q} 32 ; \mathrm{p} 13)$, dir ins $(9 ; 12)(\mathrm{q} 21 ; \mathrm{p}$ ?)de novo

$46, \mathrm{XY}, \mathrm{t}(14 ; 18)(\mathrm{q} 32.33 ; \mathrm{q} 21.31)$ de novo

46,XY,inv(1)(p13q12)mat

$46, \mathrm{XX}, \operatorname{inv}(1)(\mathrm{p} 21 \mathrm{q} 41), \operatorname{inv}(5)(\mathrm{q} 13 \mathrm{q} 34)$ de novo

$46, \mathrm{XY}, \mathrm{t}(1 ; 3)(\mathrm{p} 22 ; \mathrm{q} 27)$ pat

46,XY,t $(1 ; 7)(\mathrm{p} 32 ; \mathrm{p} 11)$ unknown

$46, X X, t(1 ; 11)(p 13 ; p 11)$ de novo $^{39}$

$46, \mathrm{XY}, \mathrm{t}(1 ; 15)$ (q12;q11)de novo

$46, \mathrm{XY}, \mathrm{t}(1 ; 16)$ (q12;p13) unknown ${ }^{40}$

$46, \mathrm{XY}, \operatorname{inv}(2)(\mathrm{p} 11 \mathrm{q} 14)$ pat

$46, \mathrm{XY}, \mathrm{t}(2 ; 3)$ (q31.2; 11.1$)$ unknown

$46, \mathrm{XY}, \mathrm{t}(2 ; 3 ; 7)$ (q14;q25;q34) unknown

$46, \mathrm{XX}, \mathrm{t}(2 ; 4 ; 6 ; 9 ; 10)$ (p12;q12;q23;q12;pter)unknown

$46, \mathrm{XX}, \mathrm{t}(2 ; 5)(\mathrm{q} 22.3 ; \mathrm{q} 33.1)$ de novo

$46, \mathrm{XY}, \mathrm{t}(2 ; 6)$ (p23; 15$)$ unknown

$46, \mathrm{XX}, \mathrm{t}(2 ; 9)(\mathrm{p} 23 ; \mathrm{q} 22)$ de novo

$46, \mathrm{XY}, \mathrm{t}(2 ; 10)(\mathrm{q} 14.3 ; \mathrm{p} 12.3)$ de novo

46,XY,t(2;12)(p23;q24.1)unknown

$46, \mathrm{XY}, \mathrm{t}(2 ; 20)(\mathrm{q} 11 ; \mathrm{p} 11)$ de novo

$46, \mathrm{XY}, \mathrm{t}(2 ; 22)(\mathrm{q} 11.2 ; \mathrm{q} 11.2)$ de novo

$46, \mathrm{XY}, \mathrm{t}(2 ; 22)$ (q13;q11.1)de novo

$46, \mathrm{XX}, \mathrm{t}(3 ; 4)$ (q24;q31.3)unknown

$46, \mathrm{XY}, \mathrm{t}(3 ; 6)(\mathrm{p} 14 ; \mathrm{p} 22)$ de novo

$46, \mathrm{XX}, \mathrm{t}(3 ; 7)$ (q21;p14)de novo

$46, \mathrm{XY}, \mathrm{t}(3 ; 19)$ (p25; $\mathrm{q} 13)$ de novo

$46, \mathrm{XY}, \mathrm{t}(4 ; 7)(\mathrm{q} 34 ; \mathrm{q} 31)$ unknown $^{40}$

46,XX,t( $4 ; 7 ; 14)(\mathrm{q} 13 ; \mathrm{q} 23 ; \mathrm{q} 24)$ unknown

$46, \mathrm{XY}, \mathrm{t}(4 ; 14)$ (q12;q24.1)de novo

46,XY,t $(4 ; 16)$ (q24;p13.2) unknown

$46, \mathrm{XX}, \mathrm{t}(4 ; 17)$ (q21;q23)de novo

$46, \mathrm{XX}, \mathrm{t}(4 ; 20)$ (q;p)de novo

$46, \mathrm{XX}, \mathrm{t}(4 ; 22)(\mathrm{q} 31.3 ; \mathrm{q} 12.2)$ de novo

46,XY,inv(5)(p13p15),inv(9) unknown ${ }^{39}$

$46, \mathrm{XX}, \mathrm{t}(5 ; 12)$ (q13;13)unknown

$46, \mathrm{XY}, \mathrm{t}(5 ; 14)(\mathrm{q} 11 ; \mathrm{p} 12)$ de novo

$46, \mathrm{XX}, \mathrm{t}(5 ; 20)(\mathrm{q} 12 ; \mathrm{p} 11) \mathrm{mat}$

$46, \mathrm{XY}, \mathrm{t}(5 ; 16)(\mathrm{q} 14.1 ; \mathrm{p} 11.2)$ de novo

46,XY,inv(6)(p22q21)pat

46,XY,inv(6)(p24q23)mat

$46, \mathrm{XX}, \mathrm{t}(6 ; 8)$, dir ins $(11 ; 12)(\mathrm{p} 15.1 ; \mathrm{q} 13 \mathrm{q} 21.3)$ de novo

$46, \mathrm{XY}, \mathrm{t}(6 ; 13)(\mathrm{p} 21.2 ; \mathrm{q} 33.3)$ de novo 
Appendix Continued

Phenotype

\begin{tabular}{|c|c|}
\hline Phenotype & Karyotype \\
\hline & $\begin{array}{l}\text { 46,XX,t(6;14)(q13;q32)pat }{ }^{41} \\
\text { 46,XY,t(6;22)(p22;q12)de novo } \\
\text { 46,XY,t(7;12)(q11;q13)mat } \\
\text { 46,XY,t(7;12)(q21.4;q15)de novo } \\
\text { 46,XX,t(7;13)(q21;q21)de novo } \\
\text { 46,XY,t(7;19)(q11.21;p13.1)de novo } \\
\text { 46,XX,t(7;22)(p15;q12)mat } \\
\text { 46,XX,inv(8)(p22q22)unknown } \\
\text { 46,XY,t(8;19)(q24;q12)unknown } \\
\text { 46,XX,t }(9 ; 10)(\mathrm{p} 12 ; \mathrm{q} 11.2) \text { de novo } \\
\text { 46,XY,t(9;12)(p21;q24)de novo } \\
\text { 46,XX,inv(10)(p11q21)mat } \\
\text { 46,XX,inv(10)(p13q22)mat } \\
\text { 46,XY,t(10;12)(p15;p11)de novo } \\
\text { 46,XY,t(10;13)(q24;p11)unknown } \\
\text { 46,XX,t(10;15)(q22;q24)de novo } \\
\text { 46,XY,t(10;16)(q21;q11)de novo } \\
\text { 46,XX,t(10;18)(q11;q12)de novo } \\
\text { 46,XY,t(11;14)(q25;q24.3)de novo } \\
\text { 46,XX,inv(12)pat } \\
\text { 46,XY,inv(12)(p13q13)pat } \\
\text { 46,XY,t(12;14)(q14;q13)de novo } \\
\text { 46,XX,inv ins (15;5)(q15;p15.2p14.1)de novo } \\
\text { 46,XY,t(15;18)(p13;q11)unknown } \\
\text { 46,XY,t(16;17)(p11;q21)mat } \\
\text { 46,XX,inv(20)(p11q12)pat } \\
\text { 46,X,t(X;1)(q28;p25)unknown } \\
\text { 46,X,t(X;4;13)(p11.1;q12;q22.2)unknown } \\
\text { 46,X,t(X;7)(q22;p22)unknown } \\
\text { 46,X,t(X;10)(p11;q26)unknown } \\
\text { 46,X,t(X;15)(p22;q11)unknown } \\
\text { 46,X,t(X;17)(p11.2;p13.2)de novo } \\
\text { 46,X,inv(Y)de novo }\end{array}$ \\
\hline
\end{tabular}

